\title{
Coir Pith - A Medium for Oil Absorption
}

\author{
P.S. Parameswaran ${ }^{1}$, Anita Das Ravindranath $^{2}$ and U.S. Sarma ${ }^{3}$
}

\begin{abstract}
Coir pith, the byproduct of coconut husk, due to its abundance nature and its porous structure can be effectively used for oil adsorption. Modification of coir pith to make as hydrophobic may allow them to be used for oil adsorption. Oil spills can destroy marine aquatic life and have a great impact on environment. In this study coir pith have been treated enzymatically (Lipase, Protease \& Glucanase) and chemically (Acetylation) to impart hydrophobicity and to enhance oil adsorption capacity. The coir pith samples were characterized periodically by FTIR, SEM. The extent of acetylation was evaluated by weight percent gain. The results suggests that acetylated coir pith could be beneficial in oil adsorption and potentially provide a low cost environmentally friend adsorbent for oil spill.
\end{abstract}

Key words: Coir pith, Lipase, Protease, Glucanase, Acetylation, Oil adsorption capacity.

\section{Introduction}

Lignocellulose biomass, comprising primarily of forestry, agricultural and agro-industrial wastes constitute an abundant, renewable inexpensive energy source (Kavitha and Namasivayam, 2007). Lignocelluloses are complex biomass, where carbohydrates such as cellulose and hemicelluloses are tightly bound to lignin molecules. The use of lignocelluloses as a sorbent in oil spillage is gaining acceptance in recent times (Bodirlau and ATeacaRom 2009, Moses et al. (2004). The major constituents of the lignocelluloses are cellulose, hemicellulose and lignin. Cellulose is $\beta-(1-4)$ linked polymers of glucose made of cellobiose units with about 2000 to 27000 glucose residues. These chains are packed by hydrogen bonds in so called "elementary fibrils" originally considered to be $3-4 \mathrm{~nm}$ wide and contain about 36 chains. These elementary fibrils are then packed in so called micro fibrils. These fibrils are attached to each other by hemicelluloses, amorphous polymers of different sugars as well as other polymers such as pectin and covered by lignin. The micro fibrils are often associated in the form of bundles of macro fibrils (Taherzadeh and Karimi 2007, Delmer and Amor 1995). The high resistance to natural degradation by microorganisms is mainly due to its complex chemical structure. Sometimes, accumulation of slowly decaying lignocellulose wastes also causes severe environmental hazards.

\footnotetext{
${ }^{1}$ Ex-Scientist in Charge, National Institute of Oceanography, Regional Centre, Kochi, Kerala, India.

${ }^{2}$ Director RDTE, Central Coir Research Institute, Kalavoor, Alappuzha, Kerala, India.

${ }^{3}$ Ex Director RDTE, Central Coir Research Institute, Kalavoor, Alappuzha, Kerala, India.

Corresponding Author Email address:anitadas30@gmail.com
} 
Coir pith is a lignocellulosic by-product produced during extraction of coir fiber from coconut husks and constitutes a readily available, abundant and renewable biomass. The coir pith has been experimented as a substrate for deionizing waste water, substrate for the production of bio fertilizers, biopolymers and artificial soil for plant growth (Namasivayam et al (2001). Recently, the coir pith has been investigated as a substrate for bioethanol production owing to their high cellulose content .Detailed laboratory studies have established its utility as an efficient oil absorber, with potential application in combating oil spills. The $\mathrm{ZnCl} 2$ activated coir pith carbon was reported to be an efficient adsorbent for inorganic anions such as nitrate, thiocyanate, selenite, chromium (VI), vanadium $(\mathrm{V})$, sulfate, molybdate, phosphate and heavy metals such as nickel (II) and mercury (II). Natural coir pith, comprising mostly of cellulose and hemi-cellulose is hydrophilicand an inefficient adsorber of lipophylic oil residues. Hence several chemical and biological approaches were envisaged to make coir pith more hydrophobic, thereby enhancing its oil adsorption capability. The present paper attempts at chemical and biological approaches for enhancing the oil adsorption properties of coir pith. The notion of the reactions are intended to disorganize the crystalline structure of macro and micro fibrils, in order to release the polymer chains of cellulose and hemicelluloses, and/or modify the pores in the material to enhance the oil adsorption properties.

Biological treatment involved primarily enzymatic modifications with suitable industrial enzymes like protease, lipase and glucanase. Chemical treatments included acetylation (Bledzki 1et al (2008), Diao She et al (2010), Mohd. Ghazalimohd nawawi 1 et al (2008) acid hydrolysis, Ketal formation with MIBK, acetone, etc. It was speculated that suitable derivatization of the free hydroxyl groups (of cellulose and hemi-cellulose) would reduce the hydrophilicity of coir pith rendering it a good adsorbent for hydrophobic liquids like crude petroleum oil.in addition, coir pith can potentially provide a low cost environmentally friendly adsorbent for oil spill cleanup.

\section{Material and Methods}

Material collection: Coir pith for the experimental was collected from the coir fibre extraction units in and around Alappuzha. The chemicals used for the study were of Sigma Aldrich grade.

\section{Effect of particle size on Oil adsorption properties of Coir pith:}

For the present study the coir pith was fractionated based on their size into $>0.5 \mathrm{~mm}$ and 0.5 to $1 \mathrm{~mm}$ size particles, freeze dried to constant weight and the oil adsorption efficiency was monitored. For measuring the oil adsorption properties, one gram dried coir pith was mixed with used-engine oil and the volume of oil adsorbed was calculated gravimetrically

\section{Biological treatment: Enzyme treatment studies}

Protease treatment: Proteases break up proteins into smaller peptide fragments. Proteases generally promote the hydrolysis of a peptide by activating a nucleophile, polarizing the peptide carbonyl and stabilizing the tetrahedral intermediate. Protease like all enzymes is very specific so recognizes side chain to know where to cleave. Coir pith samples were treated with protease enzyme for the time period of $1,2,3 \&$ 4 hours and the enzyme treated samples were analyzed for the oil adsorption efficiency.

Lipase treatment: Lipase includes enzymes that hydrolyze lipids, fatty acids, and acyl glycerides, including phosphoglycerates, lipoprotems, diacylglycerols, and in plants, lipids are used as structural components to limit water loss and pathogen infection. These lipids include waxes derived from fatty acids, as well as cutin and suberin. Coir pith samples were treated with lipase enzyme for different time intervals $(1,2,3$ $\& 4$ hours) and the oil adsorption efficiency of the treated samples was determined.

Glucanase treatment: Glucanase enzymes promote the hydrolysis of $\beta$ - glycoside linkages in the cellulose. The coir pith sample was treated with glucanase enzyme for varying time intervals and the oil adsorption efficiency is evaluated gravimetrically. 
Chemical treatment 1. Acetylation: Figure 1 shows process of Acetylation which was carried out by refluxing coir pith with acetic anhydride and pyridine (10:1) ratio for varying time durations (3, $612,18 \& 24$ hours). Oil absorption efficiency of the samples was evaluated gravimetrically.

2. Estimation of acetate groups in acetylated coir pith

The percentage of acetyl groups in different samples was determined by saponification method. $0.1 \mathrm{~g}$ of samples was saponified with aq. $\mathrm{NaOH}$ solution for thirty minutes. The filtrate analyzed for the excess $\mathrm{NaOH}$ remaining after saponification by titrimetric methods. The amount of sodium hydroxide consumed for saponification proportional to the amount of acetylated group in the samples.

3. Acid hydrolysis: The Acid hydrolysis was carried out by using $12 \% \mathrm{HCl}$ for 48 hours.

\section{Ketal derivative formation:}

a. With acetone: Figure 2 shows the reaction of coir pith sample with acetone in presence of $\mathrm{FeCl}_{3}$ catalyst refluxed for 24 hours.

b. With MIBK: The coir pith sample was refluxed with Methyl isobutyl ketone (MIBK) in presence of catalytic amount of the $\mathrm{FeCl}_{3}$ for 48 hours.

\section{Methanolysis}

Figure 3 shows the process of Methanolysis of coir pith was carried out by refluxing coir pith with methanol and catalytic amounts of conc. $\mathrm{HCl}$ for 32 hours.

\section{Preparation of Activated Carbon from coir pith}

Activated carbon is produced by anaerobic heating of coir pith at $435^{\circ} \mathrm{C}$ in a muffle furnace for a time period of 2 hours. The physical properties likepH, particle density, bulk density and porosity of the activated carbon were determined using standard procedures (Kumar and Chinnaiya 2009, Franklin e. Barton et al (1988). The Infra red spectrum of samples were recorded in SHIMADZU FT-IR Instrument (Model: IR Prestige 21) while the SEM analysis was carried out by TESCAN VEGA3. Oil adsorption studies of coir pith and modified coir pith samples were determined gravimetrically as per standard procedure.

\section{Calculation of oil adsorption efficiency}

The oil adsorption efficiency of natural coir pith and treated samples were determined gravimetrically by ASTM F $\mathbf{7 2 6}$ method. The efficiency of oil adsorption of different samples was calculated using the equation:

Oil adsorption efficiency $(\mathcal{E})=\mathrm{N}_{1}-\mathrm{N}_{0} \times 100$

$$
\mathrm{N}_{0}
$$

Where $\mathrm{N}_{1-}$ weight of coir pith after oil adsorption

$\mathrm{N}_{0}$ - initial weight of coir pith

\section{Characterization of treated coir pith samples using FTIR and SEM}

SEM analysis: SEM studies could reveal the surface topography and structure of the samples. Figure 4 shows the SEM analyses of both enzyme-treated and chemically treated samples were recorded and compared with that of intact coir pith for distinguishing any morphological changes during the treatment processes. It was observed that prolonged acetylation $(>12 \mathrm{hrs}$ ) leads to rupturing of the porous structure of coir pith. In activated carbon the whole polymer lattice was found ruptured. Rupturing of polymer lattice destroys thecapillaries, but increases the surface area of the adsorbent.

FT-IR analysis of the samples: Infra red (IR) spectrum of organic molecules yield valuable information on different functional groups present in them. In the present study, the IR spectra of coir pith and various derivatives thereof were recorded using a diffuse reflectance assembly. Prior to that the sample was ground to a fine powder with dry $\mathrm{KBr}$ and the homogenous solid solution containing 1-2\% of the substance was used for recording IR spectra. Figure 5 
Cord 2019, 35 (1)

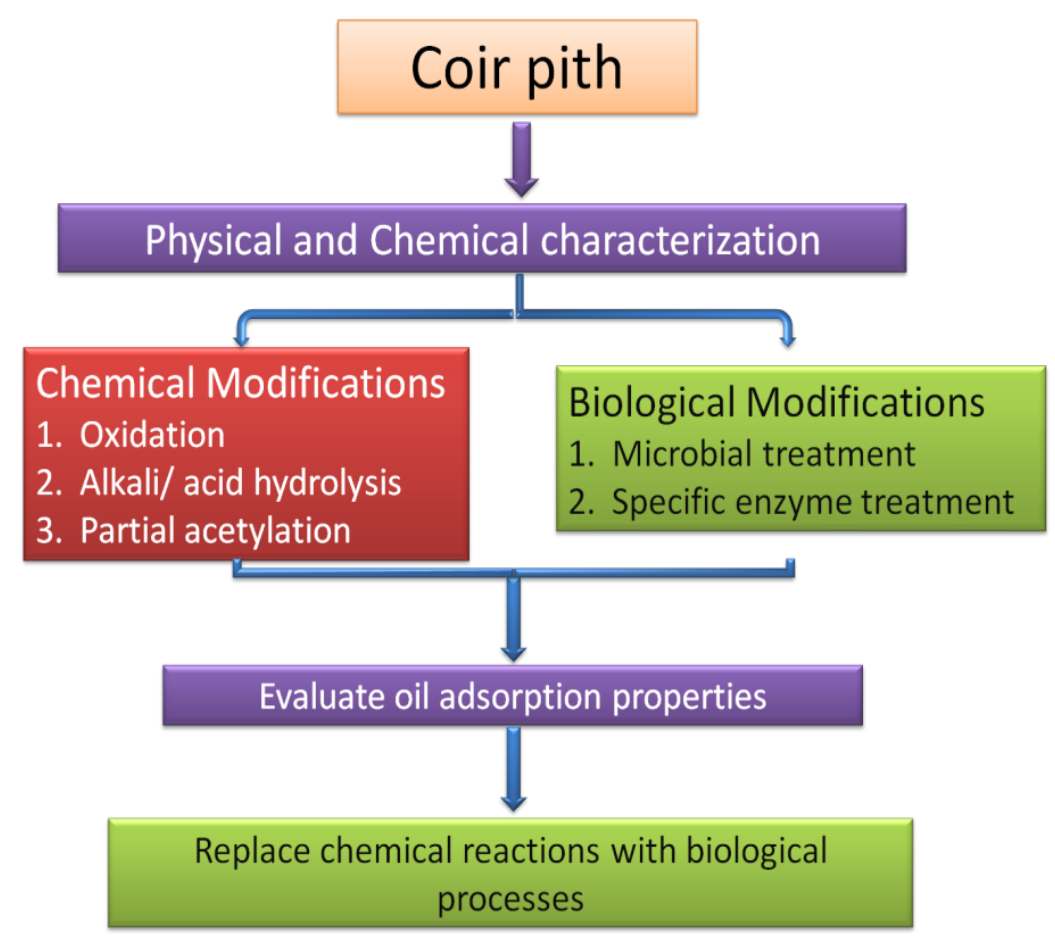

Scheme 1 Reaction process

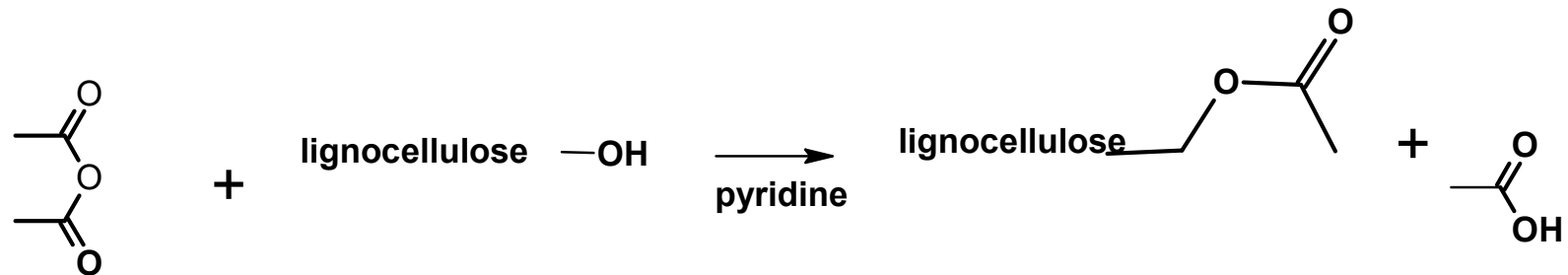

Figure 1. Mechanism of acetylation

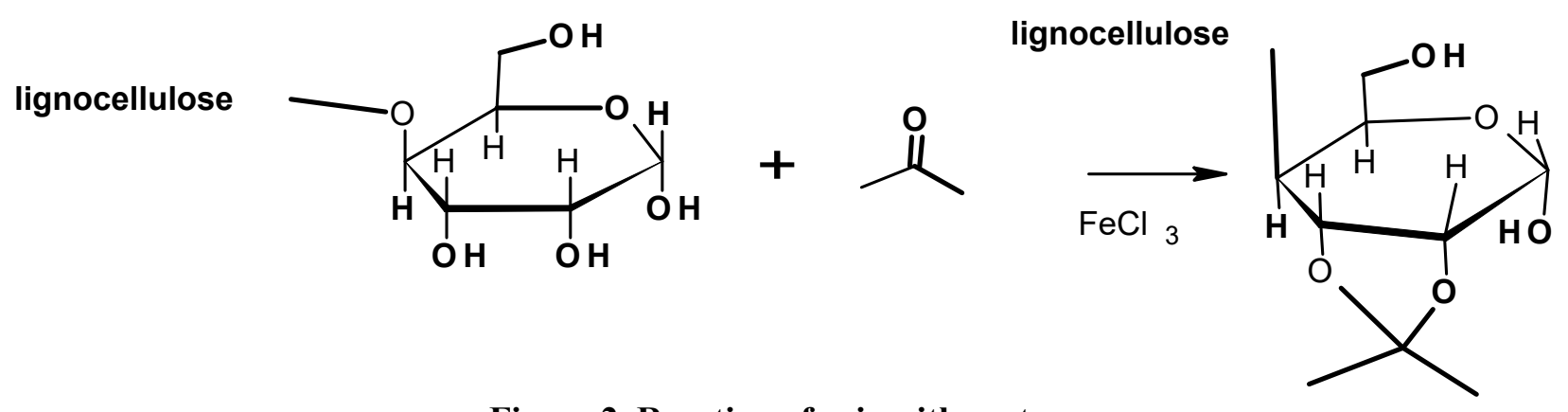

Figure 2. Reaction of coir with acetone 
Cord 2019, 35 (1)

$$
\text { lignocellulose }-\mathrm{OH}+\mathrm{H}_{3} \mathrm{C}-\mathrm{OH} \underset{\mathrm{HCl}}{\longrightarrow} \text { lignocellulose }-\mathrm{O}-\mathrm{CH}_{3}
$$

Figure 3. Process of Methanolysis

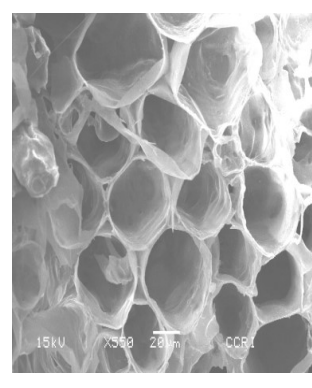

(a)

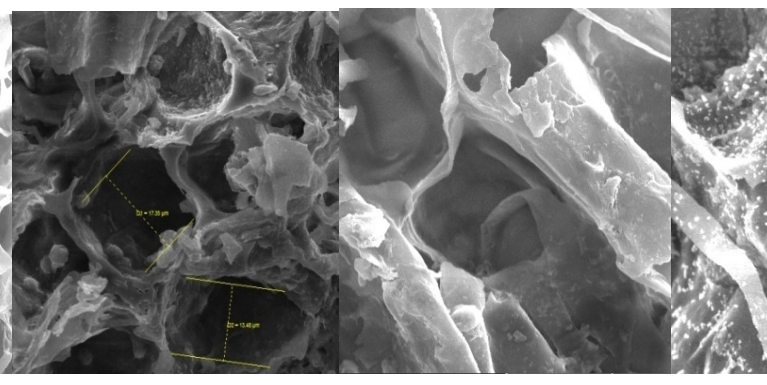

(b) (c)

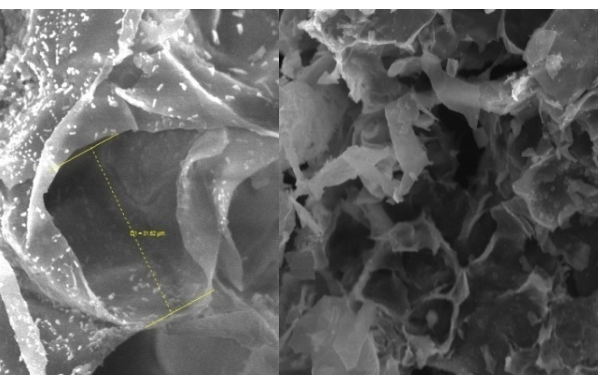

(d)

(e)

Figure 4. SEM images of (a) coir pith, (b) MIBK, (c) acetylated coir pith, (d) protease treated coir pith and (e) activated carbon

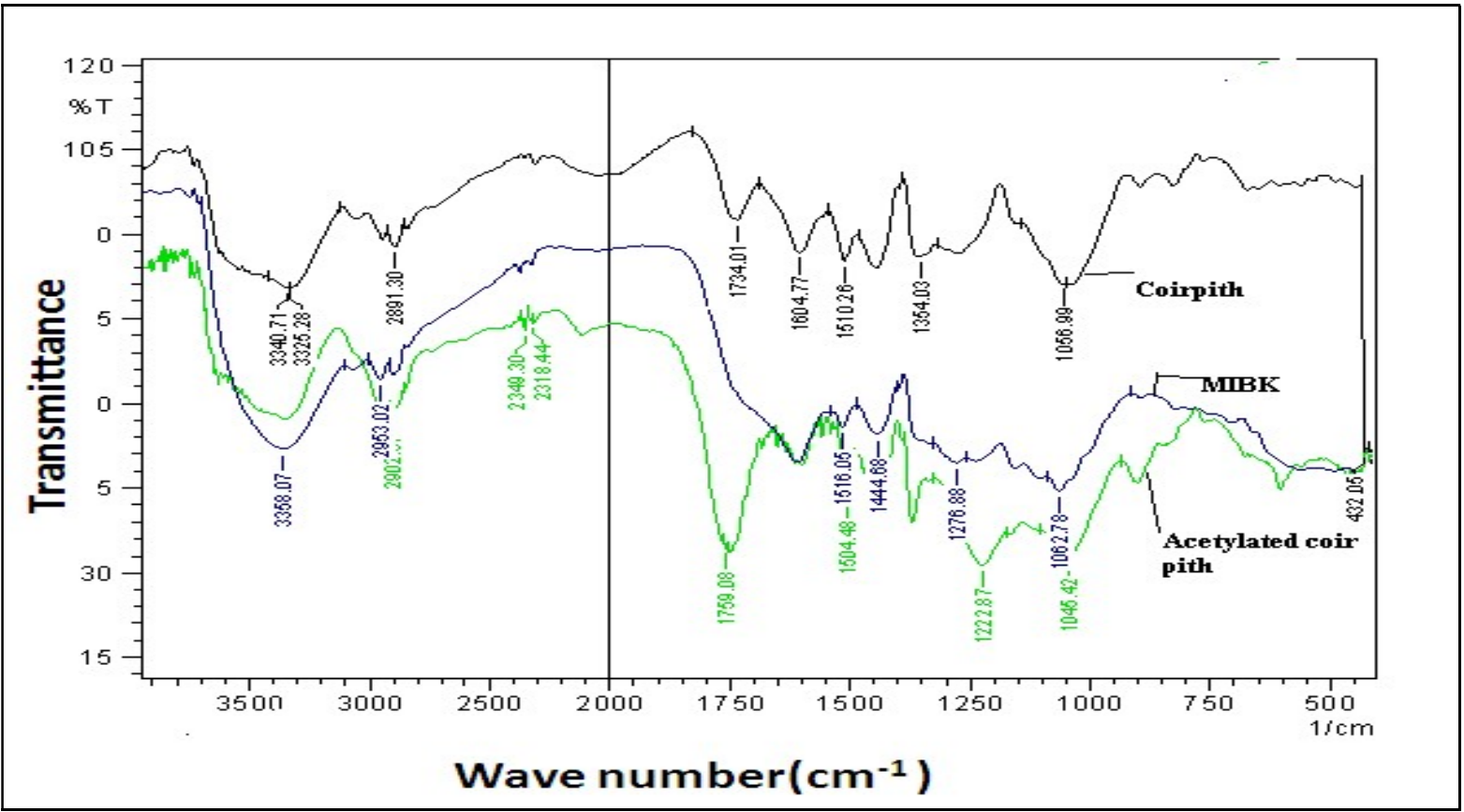

Figure 5. FTIR spectra of coir pith and its chemical derivatives 
shows IR spectra of treatedcoir pith samples. The major peaks at $3400,2900,1730,1600 \&$ $1510 \mathrm{~cm}^{-1}$. The peaks in the region $2800-3000$ and $3300-4000 \mathrm{~cm}^{-1}$ arise from aliphatic $\mathrm{C}-\mathrm{H}$ and $\mathrm{O}-\mathrm{H}$ stretching vibrations. The values at 1510 and $1600 \mathrm{~cm}^{-1}$ could be aromatic skeletal vibrations (of lignin), while the small absorption at $1730 \mathrm{~cm}^{-1}$ may be due to ester groups (minor component).

Figure 6 shows the acetylated coir pith, a strong IR absorption at $1742 \mathrm{~cm}^{-1}$ due to acetate ester moiety, as expected. This absorption increased in a linear manner up to 12 hours of reaction time, but decreased afterwards. Simultaneously, the band at $3358 \mathrm{~cm}^{-1}$ due to $\mathrm{O}$ $\mathrm{H}$ absorption decreased, indicating conversion of $\mathrm{OH}$ into OAc groups. The IR peak at $1240 \mathrm{~cm}^{-1}$ corresponds to the $\mathrm{C}-\mathrm{O}$ stretching frequency of acetyl groups. The absence of peak at $1700 \mathrm{~cm}^{-1}$ and $1840 \mathrm{~cm}^{-1}$ in the spectrum of acetylated samples indicates that byproduct acetic acid and unreacted reagent acetic anhydride are successfully removed from the compound.

Graph 1 displays the extent of acetylation which was determined using FTIR method from the ratio of the intensity of carbonyl $(\mathrm{C}=\mathrm{O})$ stretching band at $1740-1745 \mathrm{~cm}^{-1}$ to that of C-O stretching absorption of the cellulose backbone at $1020-1040 \mathrm{~cm}^{-1}$. The value increased with reaction time up to 12 hours, but thereafter decreased, probably due to competing deacetylation reaction or collapse of capillaries or combination of both.

In the IR spectra of activated carbon (Figure 7) comprised of a peak at $2860 \mathrm{~cm}^{-1}$ corresponds to aliphatic $\mathrm{CH}_{2}$ and $\mathrm{CH}_{3}$ stretching. Peak at $1720 \mathrm{~cm}^{-1}$. The Peak around $1380 \mathrm{~cm}^{-1}$ corresponds to $\mathrm{C}-\mathrm{O}-\mathrm{C}$ stretching in carboxylic acids and esters

\section{Observations and Results}

Coir pith with particle size of $0.5-1 \mathrm{~mm}$ was chosen for both chemical and biological treatments since it showed higher oil adsorption as compared to those having particle size lower than $0.5 \mathrm{~mm}$ (Graph 2). Among the different enzyme treated samples, protease treated coir pith displayed highest oil adsorption efficiency (Graph 3, 4 \& 5).

Comparison of oil adsorption efficiency of chemically treated coir pith samples indicated the acetylated coir pith to display highest oil adsorption efficiency, followed by activated carbon (Graph 6 \& 7). The other samples (methylated and ketal derivatives) did not show any noticeable improvement in oil adsorption efficiency, perhaps due to lower product yields. In order to obtain the optimum reaction conditions for acetylation, the reaction was repeated for varying durations. It was noticed that the highest oil adsorption efficiency was shown by the sample acetylated for 12 hours. Further increase of reaction time led to a reduction in oil adsorption (Graph 8). IR spectroscopy and chemical methods revealed maximum number of acetate groups to be present in coir pith acetylated for 12 hours. While the values steadily increased up to 12 hours, reaction carried out beyond this time led to decrease in acetate content as well as reduction in oil adsorption capacity (Graph $7 \&$ Figure 6). The reduced oil adsorption and acetate content in samples treated beyond 12 hours may be due to (1) partial deacetylation due to hydrolysis /or cyclic acetal formation and (2) destruction of fine capillaries within the coir pith due to prolonged exposure to acetic acid / acetic anhydride. The process of deacetylation is depicted in (Scheme $1 \& 2$ ).

The activated carbon was characterized by the physical properties $\mathrm{pH}$, particle density, bulk density and porosity (Graph 9, $10 \& 11)$.

The granules of coir pith can be spread on the polluted area. Coir pith has higher affinity for oil and form foam - like layer after the absorption of oil. The floating layer of coir pith containing oil can be easily scooped off. Absorbed oil is conveniently recovered from the sample by mechanical squeezing and can be repeatedly used for additional oil cleanups.

The liberation of water-soluble, colored poly phenols from coir pith soaked in water is a serious drawback, preventing its wider usage as an oil spill cleaner. Our studies indicate that amount of polyphenols leaching from acetylated 


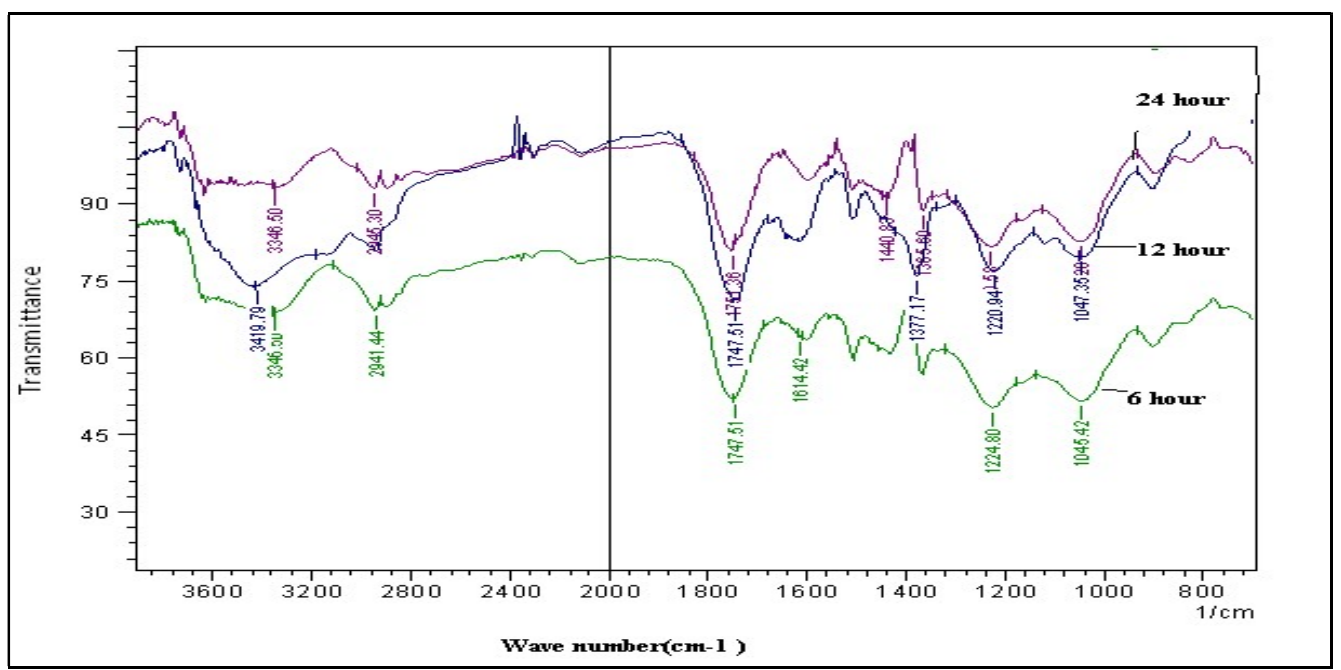

Figure 6. FTIR spectra of Comparison of extent of acetylation reaction

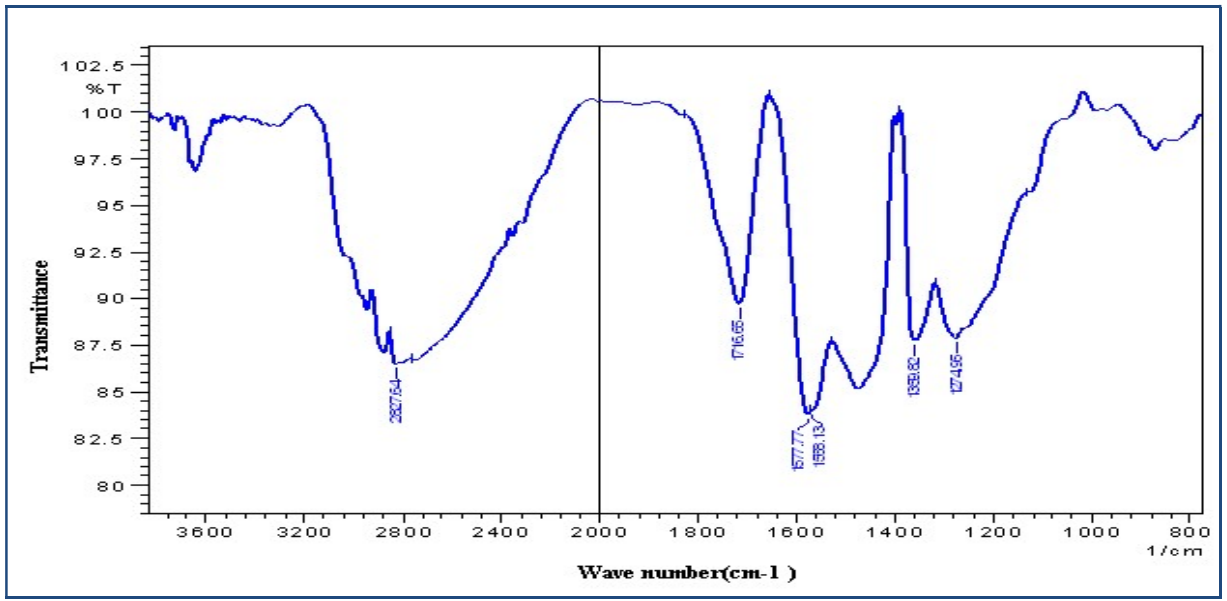

Figure 7. FTIR spectra of activated carbon from coir pith

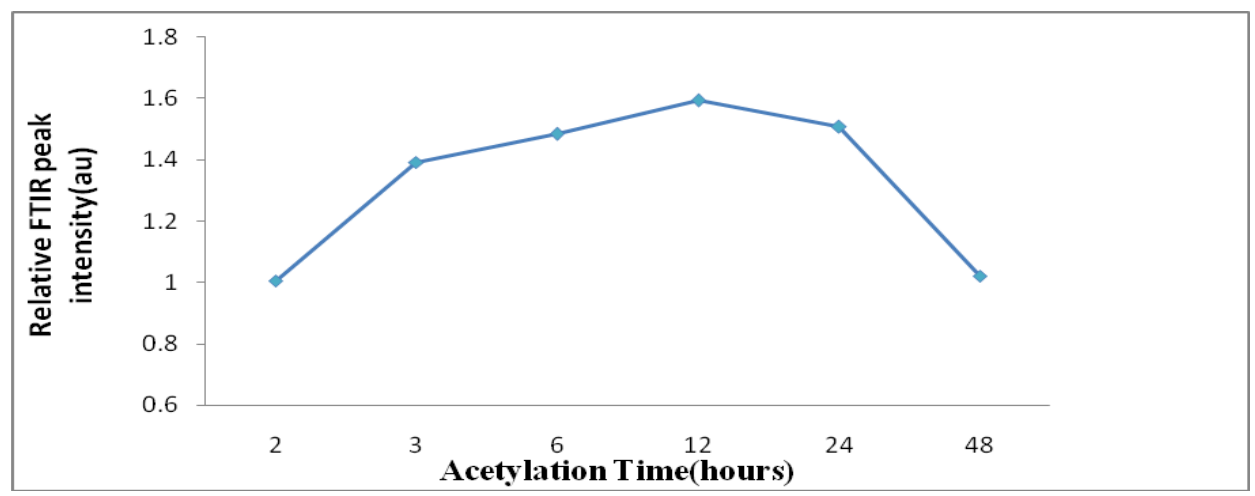

Graph 1. Comparison of the relative peak intensity of the acetylated products 


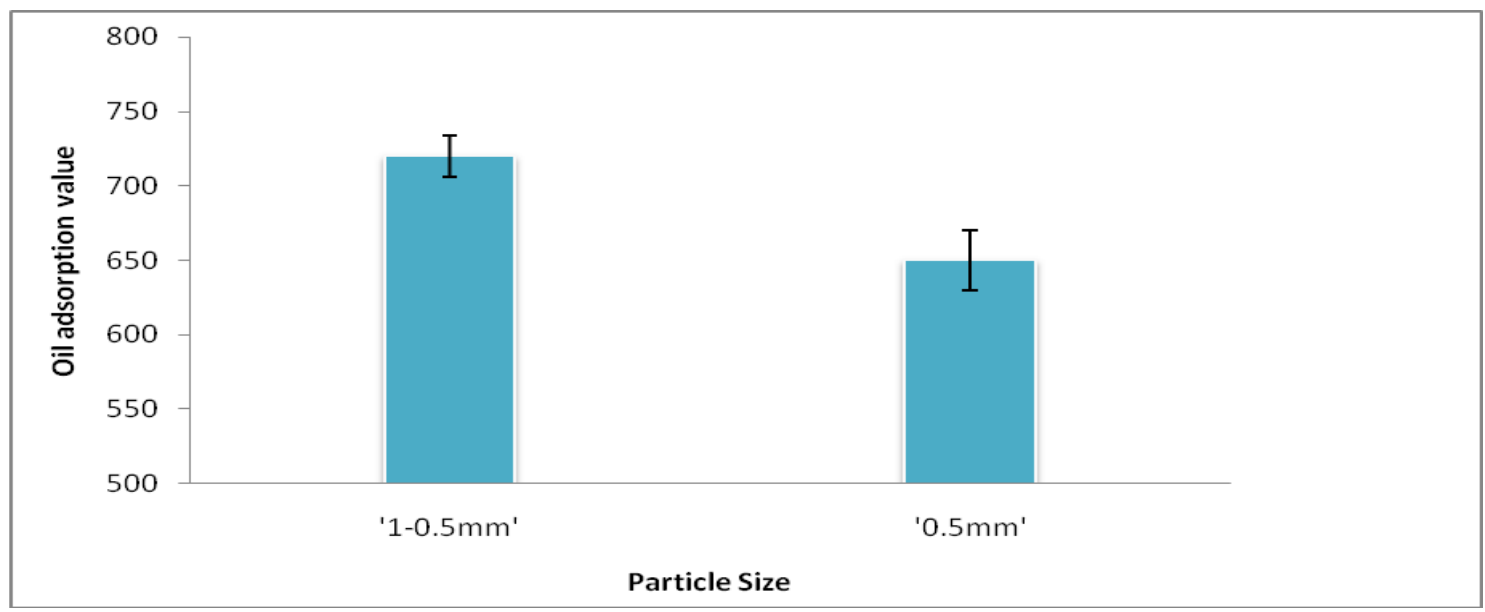

Graph 2. Effect of particle size on the oil adsorption capacity of the coir pith

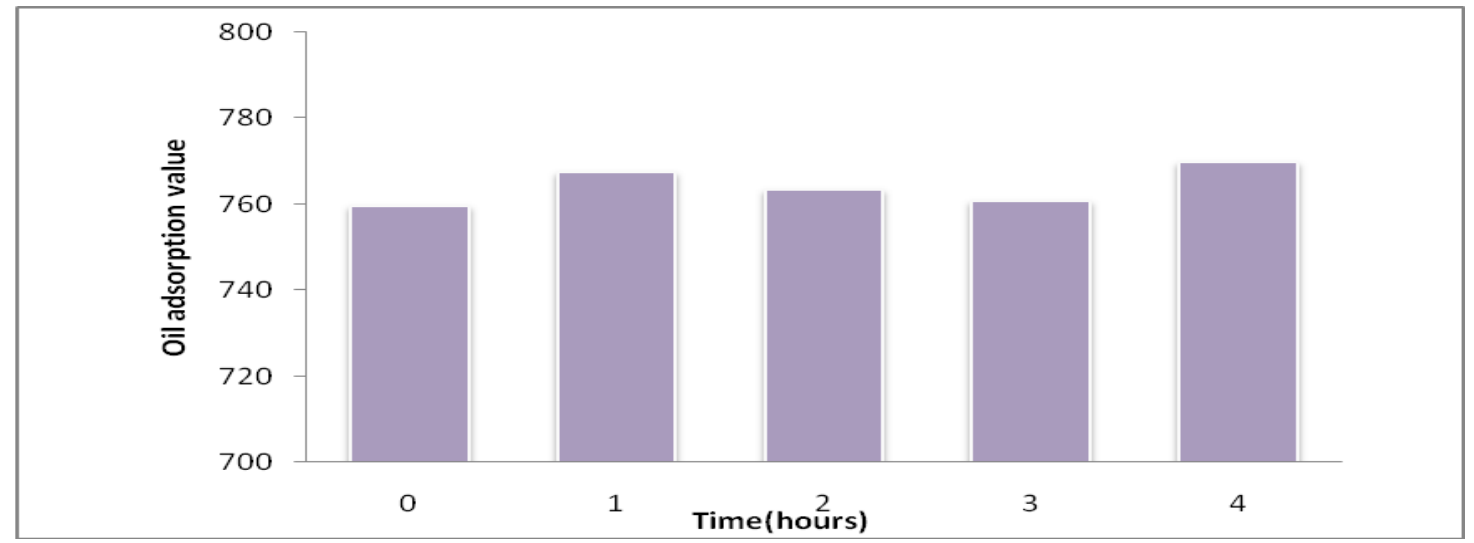

Graph 3. Comparison of oil adsorption efficiency of protease treated samples

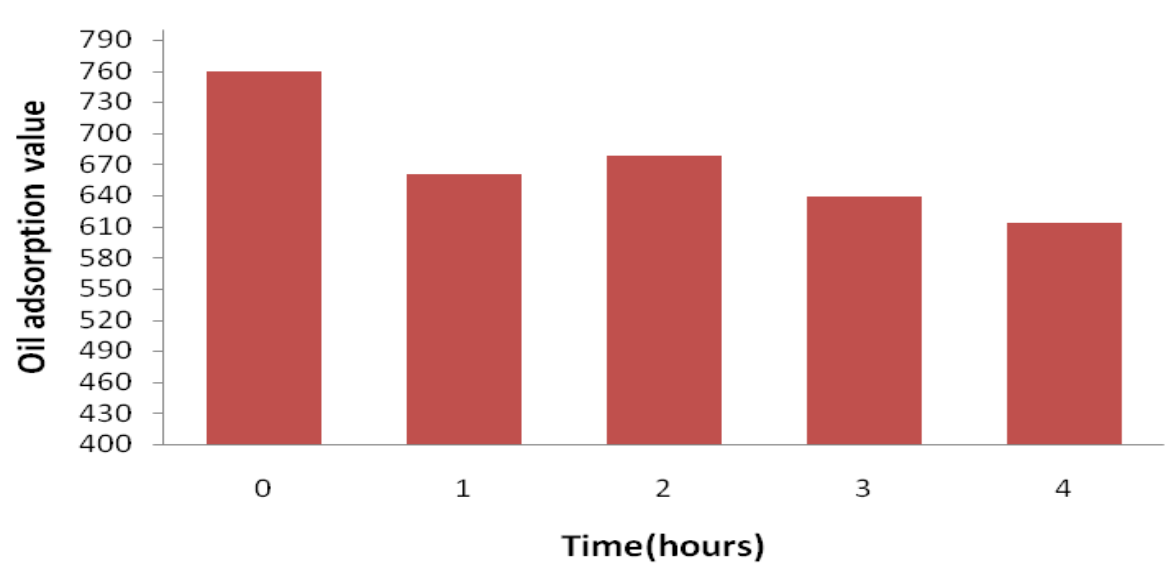

Graph 4. Comparison of oil adsorption efficiency of lipase treated samples 


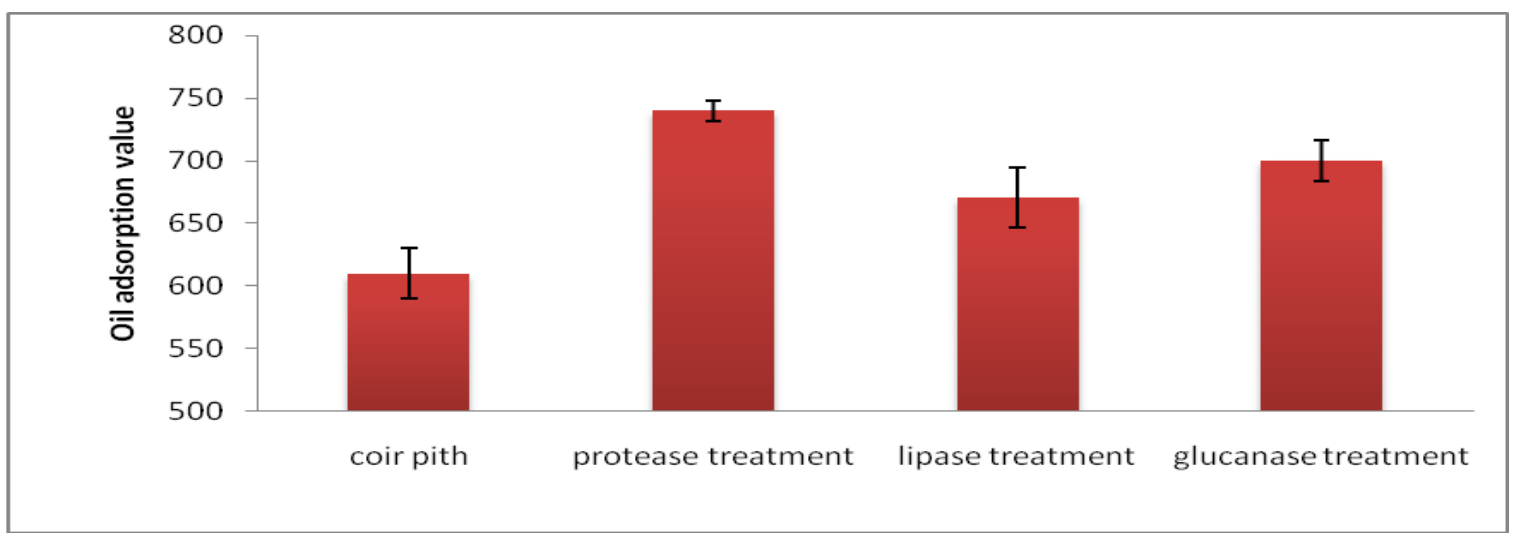

Graph 5. Comparison of oil adsorption efficiency by coir pith after different enzyme treatments

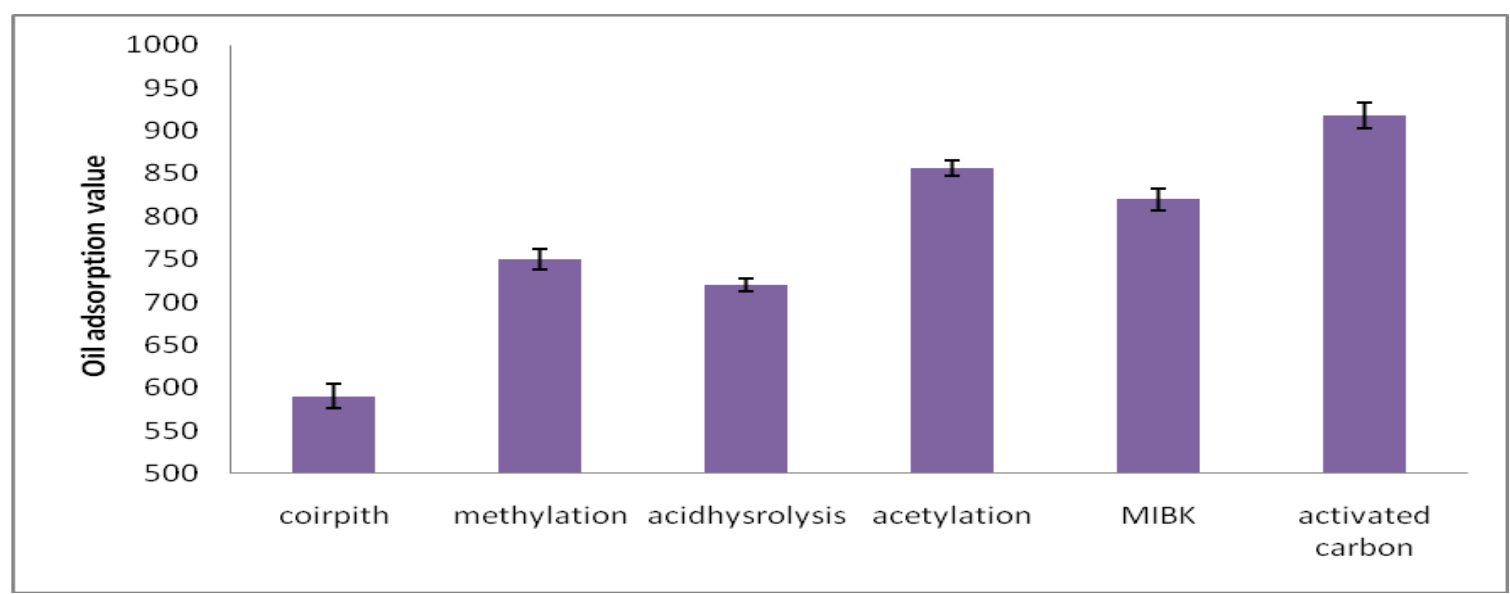

Graph 6. Comparison of the oil adsorption efficiency of chemically treated samples

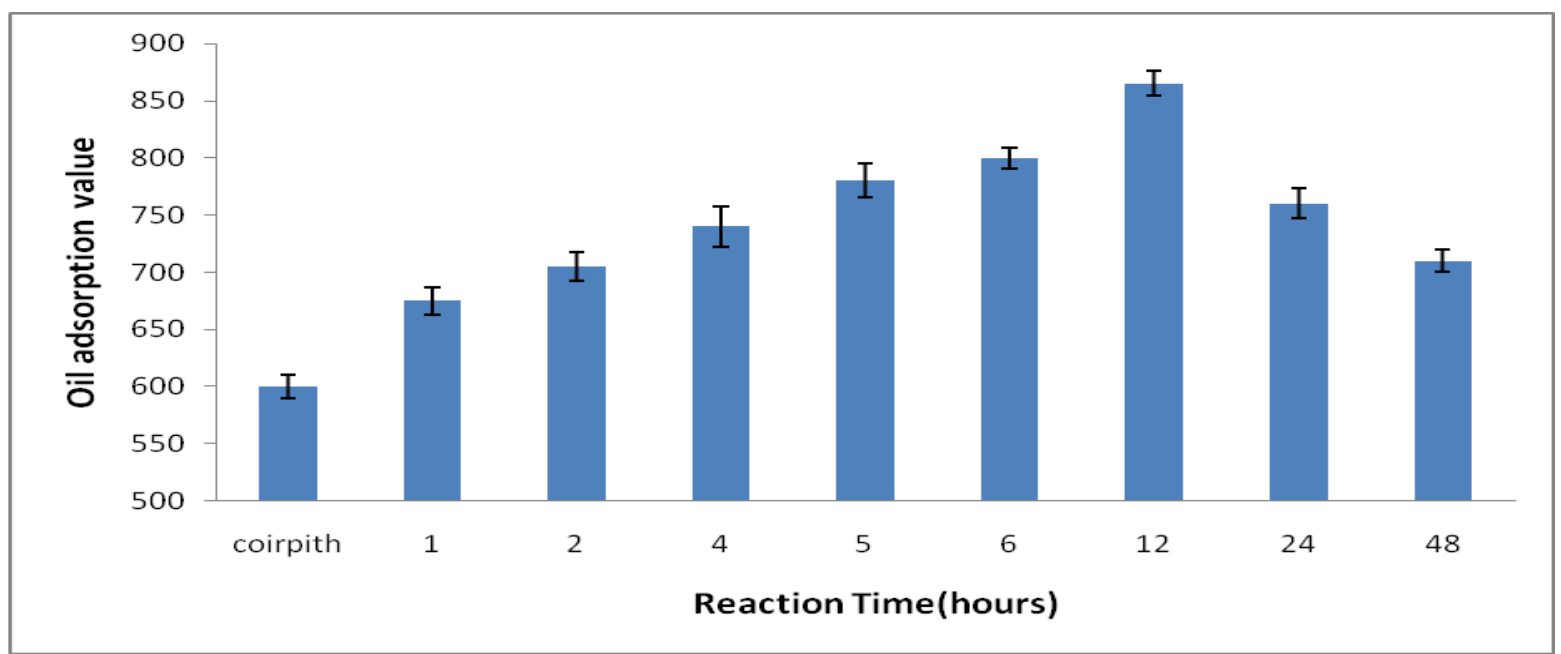

Graph 7. Comparison of the oil adsorption efficiency of different acetylated products 
Cord 2019, 35 (1)

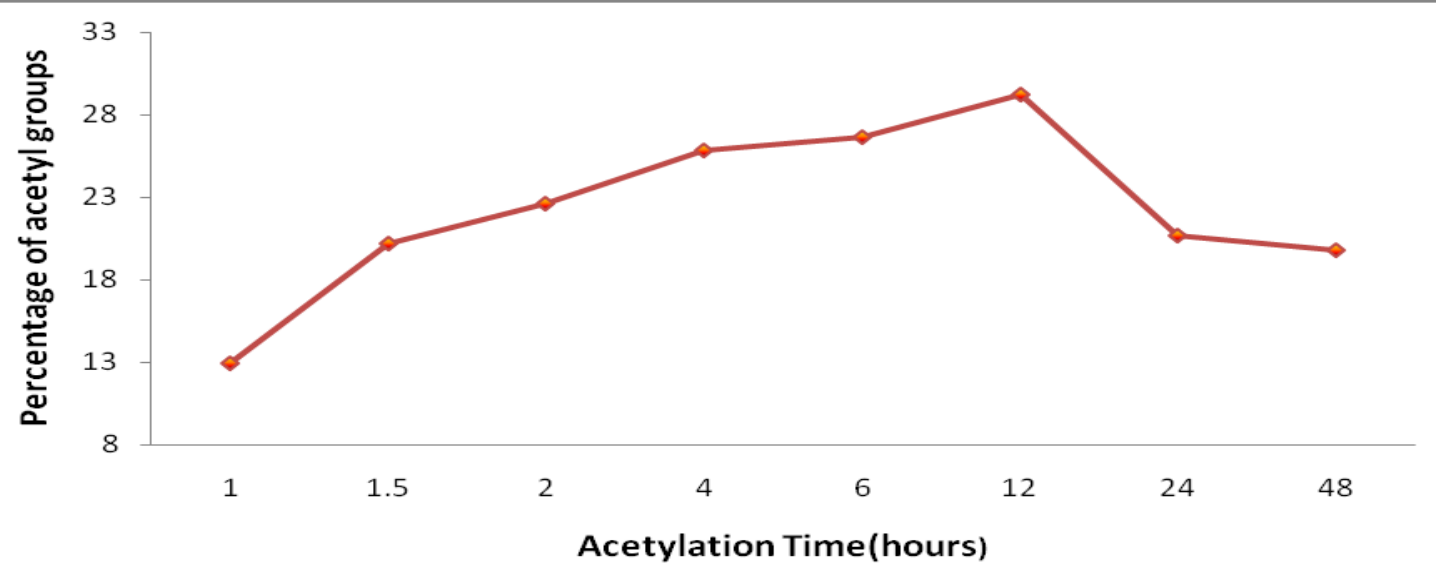

Graph 8. Estimation of percentage of acetyl groups in different acetylated samples

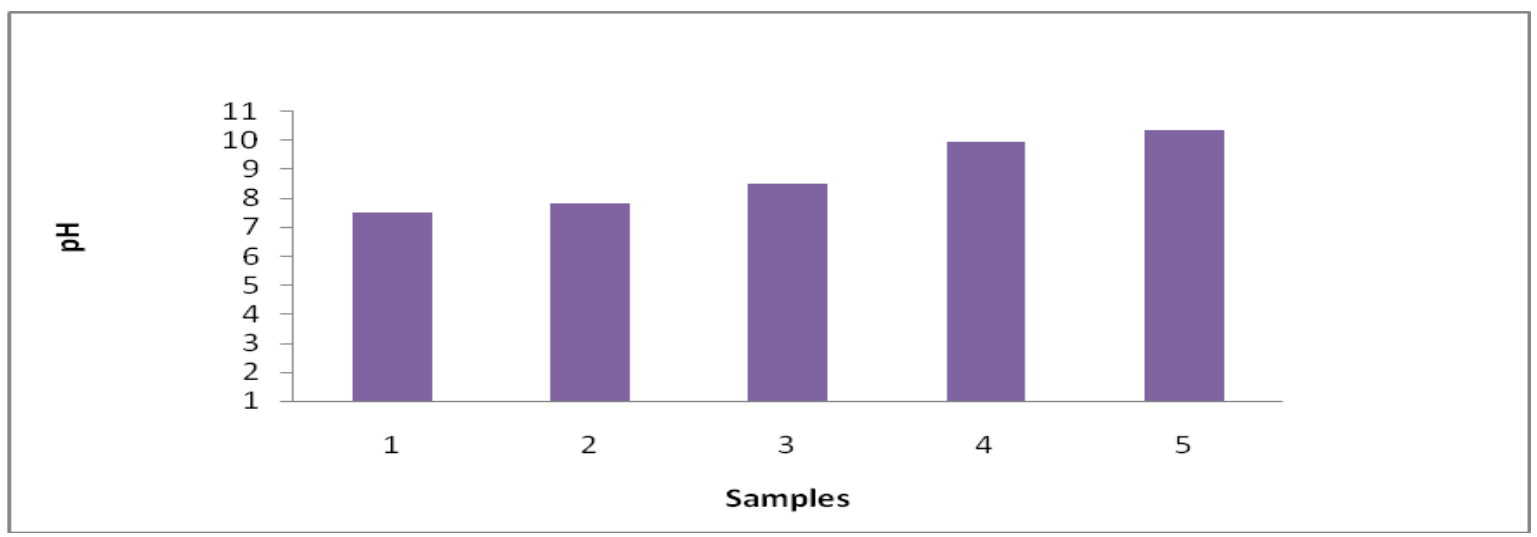

Graph 9. pH of activated Carbon

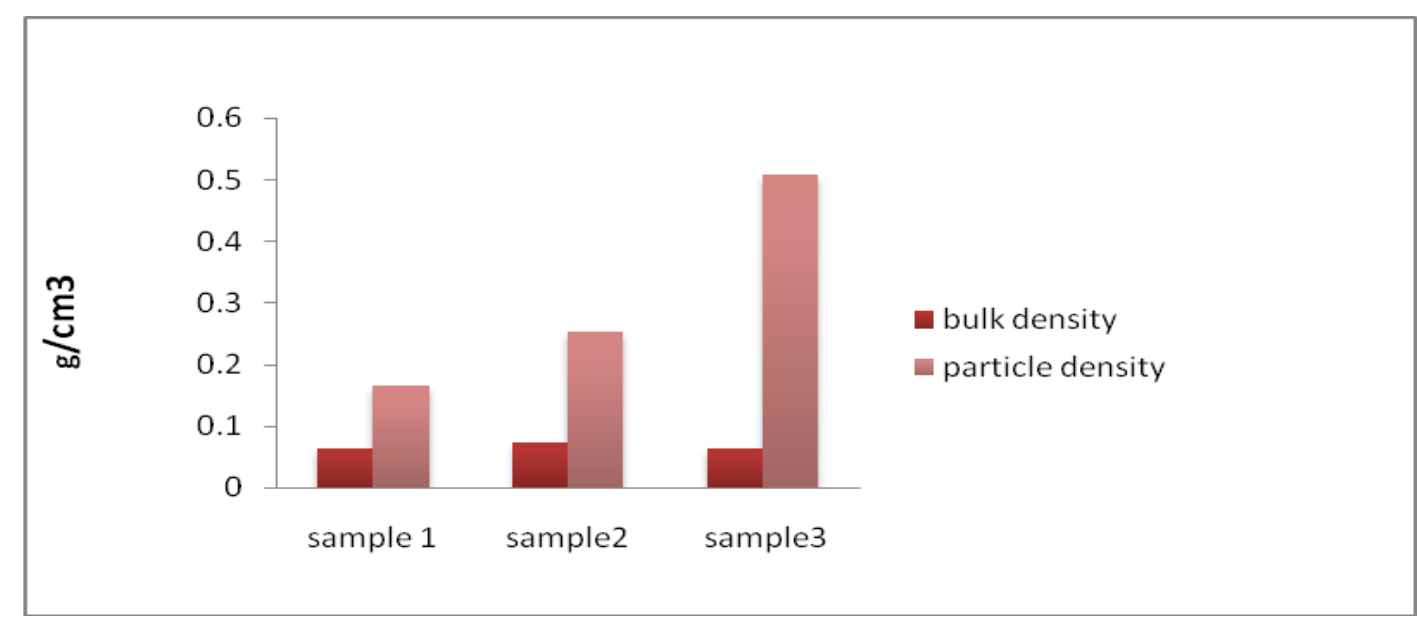

Graph 10. Particle density and bulk density of the activated carbon 


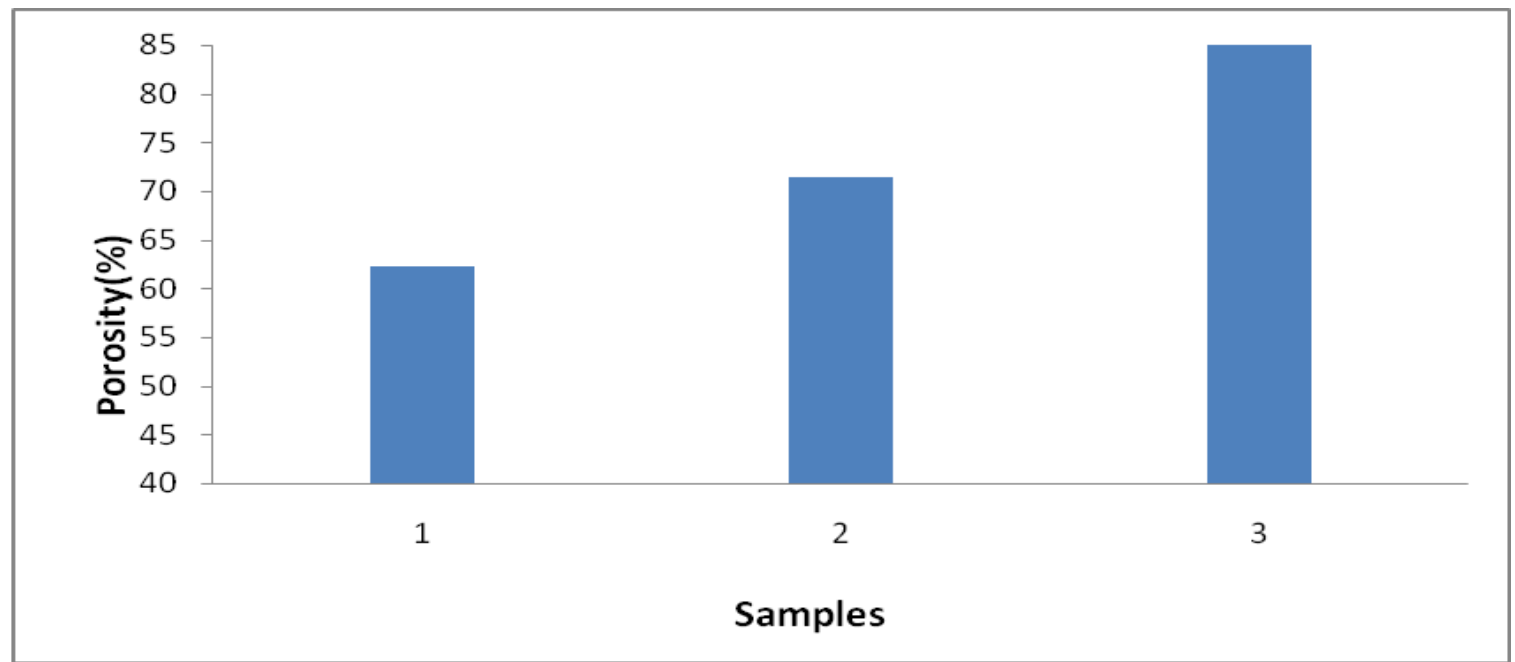

Graph 11. Porosity of the activated carbon samples

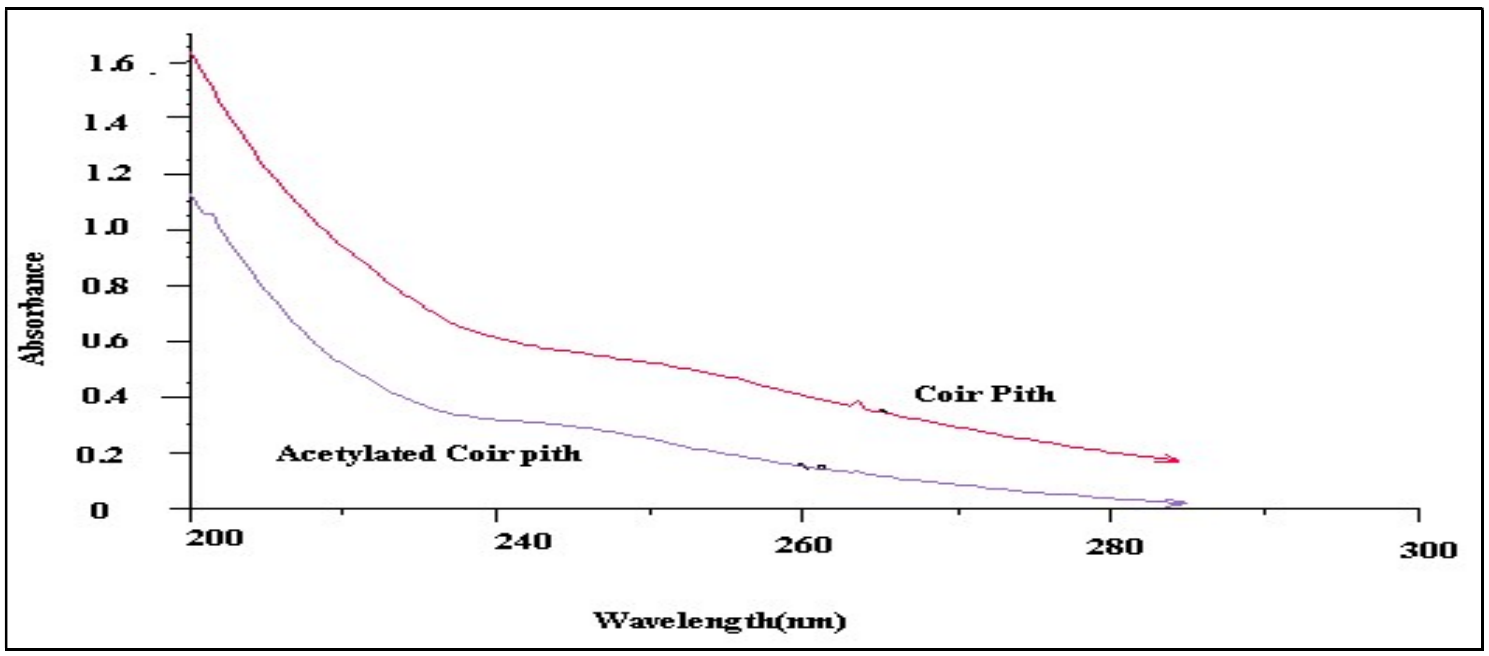

Figure 8. UV-Vis spectra of water samples after soaking Coir pith and acetylated coir pith for one week each
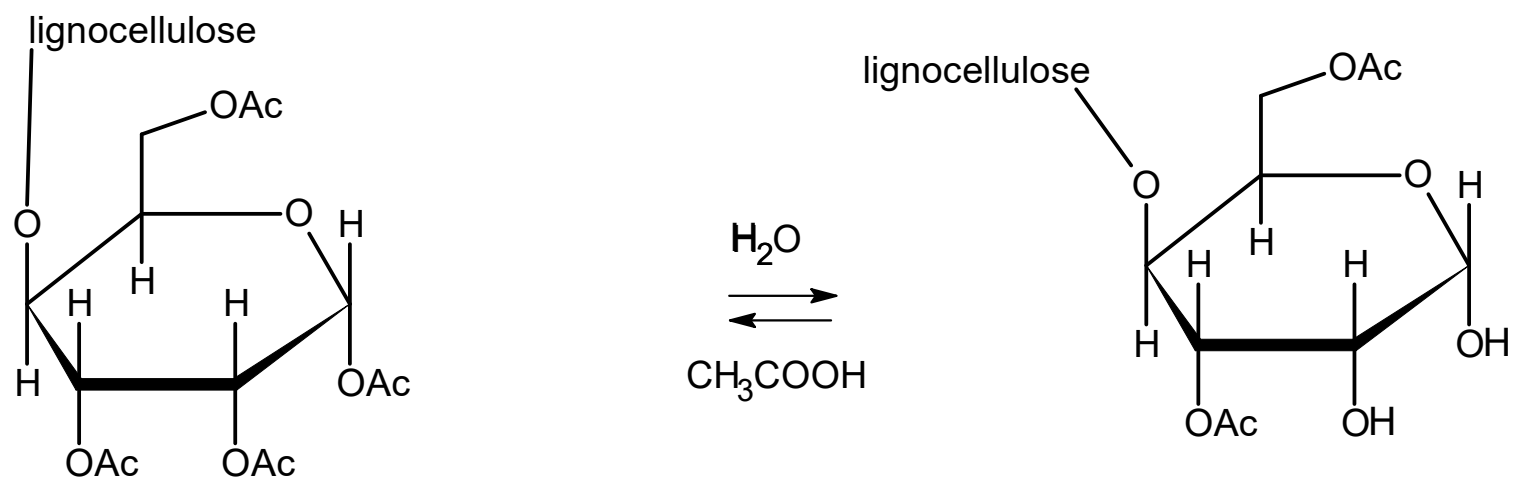

Reaction scheme 1. Deacetylation mechanism 

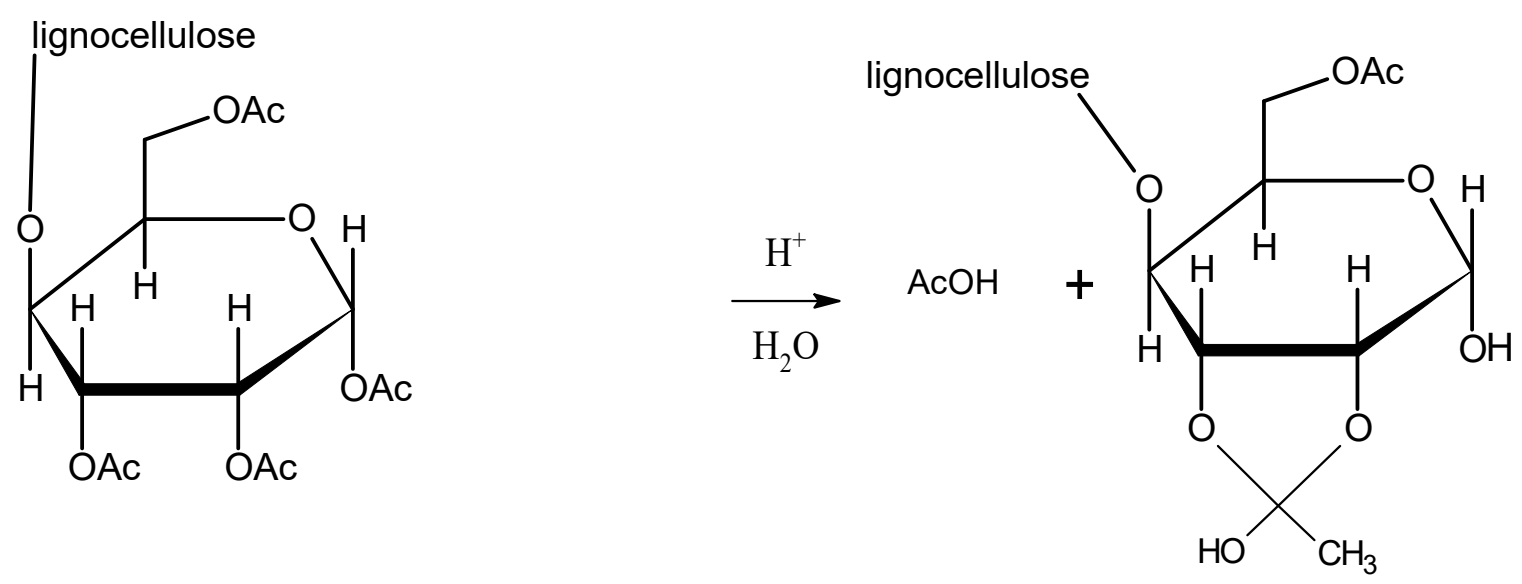

Reaction Scheme 2. Deacetylation involving cyclic structure

coir pith is much lower than natural coir pith (Figure 8).

It is estimated that cost of production of $50 \mathrm{~g}$ of acetylated coir pith using GR Grade acetic anhydride is around Rs 750.00. Efficient recovery of unreacted acetic anhydride and acetic acid, the reaction byproduct will reduce this cost further.

\section{Conclusion}

Coir pith, a byproduct of coir industry and abundantly available raw material can be converted into a value added product of potential application in environment protection. Among the different biological (enzymatic) and chemical methods tested, chemical modification involving acetylation of coir pith was found to adsorb maximum oil. About 50\% enhancement in oil adsorption by acetylated coir pith, treated for 12 hours was observed. Beyond 12 hours, the integrity of coir pith was observed to be lost due to physical crumbling and deacetylation as revealed through SEM, FT-IR and chemical methods (saponification). Acetylated sample is also more environment-friendly, due to lower leaching of poly phenols into the environment as compared to untreated coir pith and therefore the potential of coir pith can be harnessed for mopping up oil spills in water bodies and save the toxic effects to the marine life in aquatic environments.

\section{References}

Bledzki 1, A.K., Mamun 1, A.A., Lucka-Gabor 1, M., Gutowski, V.S., 2008. The effects of acetylation on properties of flax fibre and its polypropylene composites. EXPRESS Polymer Letters. 2, (6) 413422.

Bodirlau. R., ATeacaRom. C., 2009. Fourier transform infrared spectroscopy and thermal analysis of lignocellulose fillers treated with Organic anhydrides journphys, 54(1-2): 93-104 Bucharet 2009.

Delmer, D.P., Amor, Y., 1995. Cellulose Biosynthesis. Plant Cell, 7, (7), 987 1000.

Diao She, Run-Cang Sun and Gwynn Lloyd Jones, 2010. Chemical Modification of Straw as Novel Materials for Industries. Cereal Straw as a Resource for Sustainable Biomaterials and Biofuels, Book Chapter 7, 209-217.

Franklin E. Barton, II Richard B. Russell, 1988. Chemistry of Lignocellulose: Methods of Analysis and Consequences of Structure. Animal Feed Science and Technology, 21, (2-4) 279-286

Kavitha, D., Namasivayam, C., 2007. Recycling coir pith, an agricultural solid waste, for 
the removal of procion orange from wastewater. Dyes and Pigments, 74, (1), 237-248.

Kumar. R., Chinnaiya. N., 2009. Development and characteristics of activated carbons from jatropha husk, an agro industrial solid waste, by chemical activation methods. J. Environ. Eng. Manage, 19(3): 173-178.

Mohd. Ghazalimohd Nawawi 1, Norasikinothman, Aziatul Niza Sadikin \& Norhafizah, 2008. Lignocellulosic fiber media filters as a potential Technology for primary industrial wastewater Treatment. Journal Teknologi, 49, (F): 149-157.
Moses, O., Adebajo and Ray L., Frost, 2004 Acetylation of Raw Cotton for Oil Spill Cleanup Application - An FTIR and $\mathrm{C}^{13}$ MAS NMR Spectroscopic InvestigationMolecular and Biomolecular Spectroscopy, Part A. 60(10), 23152321.

Namasivayam, C., Dinesh Kumar, M., Selvi, K., Ashruffunissa Begum, R., Vanathi, T., Yamuna, R.T., 2001.Waste coir pith--a potential biomass for the treatment of dyeing waste waters. Biomass and Bioenergy, 21, (6) 477-483.

Taherzadeh, M.J., Karimi, K., 2007. Enzymebased hydrolysis processes for ethanol from lignocellulosic materials: A Review. BioResources, 2, (4), 707 - 738. 